\title{
The Active Role of Material Things: An Environment-Based Conceptual Framework to Understand the Well-Being of People with Dementia
}

\author{
Hui Ren, Megan Strickfaden \\ Department of Human Ecology, University of Alberta, Edmonton, Canada \\ Email: hren1@ualberta.ca, strickfa@ualberta.ca
}

How to cite this paper: Ren, H. and Strickfaden, M. (2018) The Active Role of Material Things: An Environment-Based Conceptual Framework to Understand the Well-Being of People with Dementia. Open Journal of Social Sciences, 6, 11-23. https://doi.org/10.4236/jss.2018.66002

Received: December 25, 2017

Accepted: May 20, 2018

Published: May 23, 2018

\begin{abstract}
This study discusses the relationships of material things to people with dementia and proposes the development of material environments to enhance their well-being. Integrating research on well-being from existential, ecological, and place-based perspectives, this study develops a new understanding of the well-being of people with dementia when considering the active role of material things in the process of developing well-being. "Well-being of people with dementia" refers to the awareness of self-existence in a real-world environment established by the interactions of people and material things. Based on this understanding, this study integrates four types of environmental embodiments, including obliviousness, watching, noticing, and heightened contact, providing specific guides to understand people's associations with their material environments. An environment-based conceptual framework, based on the new understanding of the meanings of well-being and its association with material things, allows designers and professional/family caregivers to understand the lived experiences of people with dementia, in order to enhance the well-being of their clients and their families by using material things to create a more holistic environment.
\end{abstract}

\section{Keywords}

Material Environment, People with Dementia, Environmental Embodiment, Active Environment, Well-Being

\section{Introduction}

Material environments, the material and tangible conditions in which we live, 
have been increasingly recognized as significant to the well-being of people with dementia. Previous studies, however, have not holistically explored the meanings of material things for people with dementia, preferring instead to regard the environment as a supporting factor in dementia care. Many previous studies have focused on symptoms such as apathy (Jao, Algase, Specht\& Williams, 2015) [1] and delirium (McCusker et al., 2013) [2]; behaviors such as wandering (Algase, Beattie, Antonakos, Beel-Bates, \& Yao, 2010) [3], recognition of lunchtime (Tanaka \& Hoshiyama, 2014) [4], the use and function of rooms (Hung \& Chaudhury, 2011; Marsden, Meehan \& Calkins, 2001) [5] [6], and residents' social interaction (Campo \& Chaudhury, 2012) [7]; and abilities, such as activities of daily living (Marquardt et al., 2011) [8]. Others have focused on more general care outcomes such as quality of life (Edwards, McDonnell \& Merl, 2013; Fleming, Goodenough, Low, Chenoweth \& Brodaty, 2016; Torrington, 2007) [9] [10] [11] and well-being (Smit, Willemse, de Lange \& Pot, 2014) [12], and quality of care (Milte et al., 2016) [13]. Accordingly, many researchers have proposed design suggestions such as small-scale layouts to create more homelike environments, single bedrooms to respect residents' privacy, and loops to allow residents to wander safely (Calkins, 2009; Day, Carreon \& Stump, 2000) [14][15]. These suggestions are hard to apply in practice, because one may conflict with the other. For example, a specific design suggestion, such as a single-bed room, may aid a specific symptom, such as cross-infection, but may aggravate others, such as isolation and depression.

Such approaches, in short, ignore the active roles of material things that set up association and have meanings with people in a concrete lived situation. According to Heidegger (1962), things in the world integrate to form a unique whole, in which specific material things have specific meanings to specific people [16]. Removing things from their contexts, therefore, leaves those things isolated and meaningless. In dementia care, material things are factors in caregiving, so that depriving these things of their meaning negatively affects the goal of enhancing the well-being of people with dementia. The unique tangible objects comprising a material environment are means by which the meanings of lives can be studied. These objects are critical in the study of dementia because people with dementia usually have multiple symptoms, behaviours, and compounding disabilities. These combinations of symptoms, behaviours, and personal lifestyles mean that each individual is unique. As such, there is a need for a new approach to the well-being of people with dementia by exploring the meanings of the material environment to the individuals in that environment.

This study develops an environment-based conceptual framework to help us understand the association between material environments and people with dementia. The first aim is to discuss what well-being means to people with dementia when this well-being is driven by their surrounding material environments. Heidegger (1971) criticizes the metaphysical tradition in which beings and things are sequentially located according to time as unreasonable, because bein- 
gis understood on the basis of different beings interacting with each other in a holistic context [17]. Based on Heidegger, Sarvimäki (2006) criticizes the tradition of separating well-being into physical, mental, social and spiritual aspects, seeking instead to establish a more holistic understanding of well-being [18]. As such, this study proposes a new understanding of well-being that is driven by the material environment, integrating previous research on well-being from ecological, place-based and philosophical perspectives.

Based on this new understanding of well-being, the second aim of this study is to explore in specific terms how material things resonate with people with dementia in the real world. The meanings of things are determined in the specific situations in which they interact with people. These meanings, according to Merleau-Ponty (1962), are established by embodiment that explains people's perceptions of their surrounding environments [19]. A meaningful material environment encourages people, especially those with dementia, to be embodied and engaged, and as such, to establish meanings for material things, because "qualities of the world directly resonate with the lived body and thereby covey immediate meanings and ambiences" (Seamon, 2014, p. 3) [20]. These embodiment and engagement, in the study of Seamon (1979), have been classified into various types that cover different behaviours in people's daily lives, satisfying their needs at particular moments [21]. This project integrates these specific types of embodiment in order to provide a concrete guide to using material things in order to understand the well-being of people with dementia. The environment-based conceptual framework, based on the new understanding of meanings of well-being and its association with material things, can be used by designers and professional/family caregivers to explore the lived experiences of people with dementia, in order to enhance their clients or loved ones' well-being by using material things to create a holistic living environment.

\section{The Meanings of Well-Being to People with Dementia}

What does well-being mean to people with dementia? This is a core question for dementia care experts that has been discussed over decades from various perspectives, though there is no common agreement on its definition and dimensions (Gillett-Swan \& Sargeant, 2015) [22]. This section discusses previous studies of well-being, from three distinct perspectives that closely relate to material environments, and proposes a new understanding of the well-being of people with dementia that emphasizes the active role of material things in contributing to that well-being.

\subsection{Three Environment-Based Perspectives on Well-Being}

This study approaches well-being from existential, ecological, and place-based perspectives in order to develop an environment-based understanding of well-being. Existential understanding connects well-being directly to material environments on a philosophical level, while ecological and place-based under- 
standing establishes concrete connections between well-being and material environments. Existential well-being, from a philosophical perspective, is "a phenomenological concept referring to a feeling or experience" (Sarvimäki, 2006, p. 4) [18]. This is based on the ontological premise that people and their surrounding environments interact to establish a concrete whole in which people conduct their lived experiences and build consciousness of self (Merleau-Ponty, 1962; Wrathall, 2009) [19] [23]. The existential theory of dwelling-mobility offers a structure of well-being that breaks down the ontological understanding of wholeness into different dimensions: mobility, meaning freedom and future possibility; dwelling, meaning acceptance of one's present situation; and Gegnet, meaning the unity of dwelling and mobility (Todres \& Galvin, 2010) [24]. In other words, when people feel both free and comfortable in a specific environment, they establish well-being by perceiving their own existence.

Existential well-being, however, is not sufficient to explore the concrete relationships within people's lived experiences; such gaps can be filled by taking ecological and place-based well-being into consideration. In the ecological theory of aging, well-being is created by the balance of people and their surrounding environments. The ecological theory of aging regards the environment as one of the two significant domains in the process of creating well-being (Lawton, 1983) [25]. Fit, which is a key concept of the ecology theory of aging, is considered the ultimate criterion of compatibility between a person's capacities and his/her environmental situations (Nahemow, 2000) [26]. Based on this concept of fit, Lawton (1994) proposed a framework encompassing four determinants of a good quality of life: behavioral competence, psychological well-being, perceived quality of life, and objective environment [27]. This framework indicates a philosophy for a holistic or ecological scenario in which person-environment relationships relate to an individual's balance with his/her internal and objective environments.

If well-being from an ecological perspective is realized by the balance between people and environments, this balance, in the discussion of place-based well-being, should be driven by meaningful material things, because place and space are the sources of embodiment and, accordingly, of well-being (Nordbakke \& Schwanen, 2014) [28]. For example, Andrews and colleagues (2014) studied the non-representational theory of embodied engagement with lived experience, demonstrating the active role of the environment in the creation of well-being [29]. The therapeutic landscape theory from Gesler (1992) suggested that both the natural environment and the human-made landscape can enhance people's physical and psychological capabilities [30]. Williams (1998) builds upon this by considering the therapeutic landscape from a holistic and ecological perspective, in which physical, mental, emotional, spiritual, social, and environmental factors all interact with one another to create an overall sense of well-being [31]. Furthermore, the therapeutic landscape is used not just for healing and recovery, but also to maintain the health and well-being of people in 
their daily lives (Milligan, Gatrell \& Bingley, 2004; Williams, 2002; Willis, 2009) [32] [33] [34].

Existential well-being has not been applied to the study of dementia care as much as ecological (Diaz-Ponce \& Cahill, 2013; Jonker, Gerritsen, Bosboom\& Van der Stehen, 2004; Lawton, 1994; Lawton \& Rubinstein, 2000) [35] [36] [37] and place-based well-being (Chalfont, 2007; Gonzalez \& Kirkevold, 2014) [38] [39]. However, existential well-being addresses the original questions of why and how human beings, including people with dementia, exist in the world of material things. From this perspective, people's well-being is established by their consciousness of the surrounding world. Unlike the medical perspective, which evaluates people's consciousness according to their arousal and responsiveness (Block, Flanagan \& Güzeldere, 1997) [40], existential philosophers define consciousness as awareness of the world that uniquely allows human beings to realize and perceive their existence. From a medical perspective, the WHO (2017) has stated that dementia does not result in a decrease of consciousness [41]. However, from an existential perspective, the most common symptom of dementia, cognitive impairment, disengages people from their daily activities. This accordingly reduces people's awareness of their surrounding world, and deprives things of their meanings. Therefore, because of the direct connections between material things and the well-being of people with dementia, meaningful environments may engage people with dementia and enhance their well-being. As such, incorporating the ecological principle of balance and the place-based principle of the active role of material environments helps us develop a more concrete understanding of the well-being of people with dementia.

\subsection{Toward a New Understanding}

Well-being for people with dementia, integrating knowledge from existential, ecological, and place-based perspectives, means the awareness of self-existence in a real-world environment that is established by the integration of material things, people, and their embodiment, through which people perceive the meanings of their lives. The core of this understanding is the active role of the material environment in developing a more holistic model of well-being in which meaningful material things help people build up cognition and balance their needs for dwelling and freedom.

First, the material environment is part of the cognitive system. Previous studies have demonstrated that cognitive impairment, a common symptom of dementia, disengages people from their daily lives and reduces their awareness of the world. In this case, are these people still able to perceive their existence and relevant well-being? This question relates to cognition study, the perspective taken in this project. Unlike some previous cognitive studies that define cognition as an abstracting process of information (Wilson, 2002) [42], this study stands from the perspective considering the material environment as part of a cognitive system in which the physical body's perception, action, and introspec- 
tion largely influence the cognitive process (Wilson, 2002) [42]. This emphasis of the material environment and its interaction with the body in constructing cognition has been developed as embodied cognition, a process by which people experience and perceive things unconsciously in their everyday lives (Barsalou, 1999) [43]. During this process, recurring experiences accumulate and are transferred into long-term memory as symbols with particular meanings (Barsalou, 1999; Johnson, 1987) [43] [44]. Accordingly, the material environments that connect with such symbols may serve as cues in the case of impaired cognitive functions (Hampson\& Morris, 1996) [45].

In addition, the well-being of people, including those with dementia, is established when they accept their current situations while simultaneously looking forward to future possibilities. The existential theory of dwelling-mobility is the theory that is based on balancing these needs (Todres \& Galvin, 2010) [24]. Dwelling refers to the acceptance of one's specific situation and moment (Galvin \& Todres, 2011) [46]. For example, people who are seriously ill perceive well-being during the process of suffering illness when they are able to accept their illness and related disabilities. Mobility, on the other hand, refers to the possibility of changes in the future (Galvin \& Todres, 2011) [46]. Though these changes could be positive or negative, the potential for positive changes provides hope for people to move forward when their current living conditions are no longer satisfactory. The combination of dwelling and mobility sets up a reciprocal relationship that Todres and Galvin (2010) call "rooted flow", in which one accepts one's existing situation but is still able to look forward to future changes [24].

This dwelling-mobility model of well-being is realized when the environment incorporates the functions of place and space. According to Tuan (1977), space/spaciousness is associated with the sense of being free, which "means having the power and enough room in which to act" (p. 52) [47]. Place, in contrast, is the pause of the specific moment that "makes it possible for a locality to become center of felt value" (Tuan, 1977, p. 138) [47]. This means that, both space and place constitute a healthy existence because people need shelter and attachment, as well as autonomy and freedom. In terms of dementia care, this balance of space and place should allow people with dementia to feel secure and mobile within a material environment that has meaning to them. This process of engaging with the material environment and setting up meanings to the material things is called environmental embodiment.

\section{Environmental Embodiment}

Previous studies have proposed a new understanding of well-being of people with dementia, demonstrating the active role of material environments in the process of establishing well-being by providing potential cues to people with dementia and encouraging them to become engaged with the world around them. In order to explore people's engaging process, this section introduces the 
definition and different types of environmental embodiment, discussing specific ways in which material things resonate with people with dementia in the real world.

\subsection{Definition of Environmental Embodiment}

Environmental embodiment is defined as "the various lived ways, sensorily and motility-wise, that the body in its pre-reflective perceptual presence engages and synchronizes with the world at hand, especially its architectural and environmental aspects" (Seamon, 2014, p. 2) [20]. In this definition, perception, the use of the lived body to perceive the world, is the foundation of human-world integration. The perception of the surrounding environment comes naturally and is unique to each individual. According to Merleau-Ponty (1962), people, using their lived bodies, engage in the world and create an immediate awareness when entering an environment, which is a direct interaction aside from intelligence or consciousness [19]. He criticized the approach of separating different senses, arguing that the embodied experience is complete and not fragmented. For example, a lived body in the street should immediately and holistically perceives the rain with all five senses, with no sequence or separation of those senses (Merleau-Ponty, 1962) [19].

The experience of the world, such as the example of the rain above, is a holistic process in which people connect with the material things around them. For Heidegger (1962), the whole is greater than the sum of its parts [16]. Similarly, for Merleau-Ponty (1962), holistic perception of the world results from the integration of the various senses: "It remains a familiar domain round about me only as long as I still have 'in my hands' or 'in my legs' the main distances and directions involved, and as long as from my body intentional threads run out towards it" (P.130) [19]. This example is a meshing of his hands, legs, and whole body with his environment that creates a sense of familiarity. Such an experience is unique to each person as each individual uses his/her own body to experience his/her material environment, further influenced by the individual's past and the values established in the culture from which the person comes. This unique perception, according to Merleau-Ponty (1962), is realized by the movement of the body [19]. Seamon (2007) further explains this phenomenon as a dynamic process of communication between the flesh of the moving body and the material of the lived world: "through the moving, the body will get to where it needs to go" (p. 7) [48]. This interplay between the movement of the body and the material environment produces a unique whole, within which four types of embodiment have been identified: obliviousness, watching, noticing, and heightened contact (Seamon, 1979) [21].

\subsection{Four Types of Environmental Embodiment}

Obliviousness refers to the situation in which an individual is engaged in his/her feelings or imagination and as such has no awareness of the surrounding world. 
Watching is a passive method of connecting with the surrounding world, involving paying attention to a specific activity for a definite period of time. Noticing is a sudden attraction to objects that connect with the individual's cognition. Heightened contact is an experience in which an individual fully connects, and feels harmonious, with his/her surrounding environment (Seamon, 1979) [21]. These four types of environmental embodiment describe individuals' four levels of engagement with the material environment. According to Seamon (1979), obliviousness and watching involve the separation of the person from the environment, and are less encouraged, where noticing and heightened contact involve a merging of the person with the environment, and are more encouraged with the goal of creating a place of dwelling [21]. Differently, this study argues that all four types of embodiment are important for people with dementia. Obliviousness and watching are conducted in a space that makes people to feel free, while noticing and heightened contact are conducted in a place where people have the feeling of being protected and dwelled. As what has been discussed previously in this study, the balance of place and space that encourages both dwelling and mobility is a precondition for an environment that resonates with people.

For example, Shaw and colleagues (2016) refer to the case of a woman who appreciated the cruise-ship-inspired design of the common dining room of her senior housing facility because it reminded her of holidays she had taken on a real cruise ship with her husband. The design also created the impression of future cruises and possible adventures, even though the woman was no longer able to travel [49].This case is an example of all four types of embodiment. When she first entered this dining room, the cruise-ship style environment connected with her cognition, attracting her attention, and inspiring her to spend time in this environment (noticing). While seated in this dining room, she observes the activities of others (watching). The material environment and the behaviour of watching both encourage her to visit the dining room each day so that it becomes a routine (heightened contact). While she is in the dining room, she dreams of travelling with her loved one on a real cruise ship in the future (obliviousness). These four types of embodiment work together to create a complete process by which the material environment resonates with the individual. The cruise-ship style dining room provides a concrete built environment in which this woman can enjoy the moment of making a dream of being together with her loved one.

\section{The Environment-Based Conceptual Framework}

Based on previous research and discussion of this subject, Figure 1 illustrates a conceptual framework for the association of material environments and people with dementia. Unlike previous frameworks and models that consider the individual as the engine that drives the process of establishing well-being, the framework of this study emphasizes the active role of material environments and 


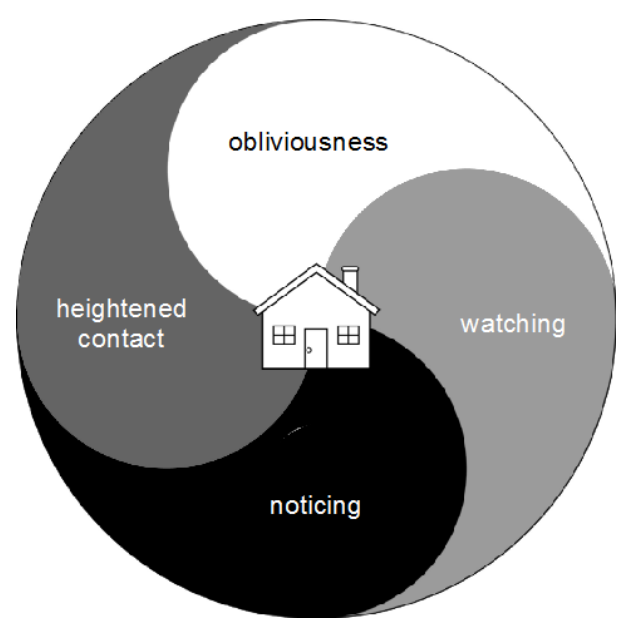

Figure 1. Environment-based Conceptual Framework for the Well-being of People with Dementia.

shows how material things endow people's lives with meaning and contribute to overall well-being.

This conceptual framework includes the following components:

- Material environment, as a part of the cognitive system, critically affects the well-being of people with dementia. An environment incorporating material things that are familiar to the individuals with dementia will cue their memories and engage them. Through their engagements with their environment, people perceive their existence and relevant well-being.

- An environment to support the well-being of people with dementia should balance place and space so that people are able to dwell and be mobile. This balancing environment should allow people to conduct different types of environmental embodiment including obliviousness, watching, noticing, and heightened contact.

- Material environment is a whole in which material things integrate with people and derive meanings from this integration. Rather than simply adding different material things together, a more holistic environment is established when these things set up different types of embodiment and become meaningful to the people.

\section{Conclusions}

This study develops a conceptual framework for a material environment that can enhance the well-being of people with dementia. This framework can be used by various participants in the dementia care process, helping them improve the quality of the living environments of people with dementia. Designers, including architectural designers, interior designers, and landscape designers, can use this framework to explore the lived experiences of people with dementia before conducting design practices. Design is a creative and subjective work in which the designers' understandings of their clients' lives strongly affect whether the design outcomes successfully address the clients' expectations when the design 
project is intended for people with special needs in caregiving. As such, in the environmental design for people with dementia, rather than simply creating designs according to fragmentary and isolated guidelines, designers should understand the continuous lived experiences of people with dementia that are affected by their material environments, and use this understanding to inspire their design practice.

In addition, caregivers, including professional caregivers and family caregivers, can use this conceptual framework to understand their clients/loved ones' lived experiences that are affected by their material environments, in order to use material things to support caregiving. For example, the caregiver can learn about the favorite songs of his/her client with dementia and understand the meanings of the music to him/her. The caregiver can then play that specific music to create an environment that may remind the specific individual with dementia of his/her past experience with his/her family and friends. The room in which the music is playing engages the individual at that specific moment and helps to establish his/her sense of well-being.

In conclusion, material things play significant roles in engaging people with dementia and helping to establish the meanings of their environment and their world. As unique tangible objects, material things reflect the lives of the people around them, and understanding the lived experience that is influenced by the material environment helps designers, caregivers, and families gain a greater understanding of the lives of people with dementia.

\section{Acknowledgements}

We would like to thank Dr. Janet Fast and the Department of Human Ecology, University of Alberta, for their helpful guidance and support.

\section{References}

[1] Jao, Y.L., Algase, D.L., Specht, J.K. and Williams, K. (2015) The Association between Characteristics of Care Environments and Apathy in Residents with Dementia in Long-Term Care Facilities. The Gerontologist, 55, S27-S39. https://doi.org/10.1093/geront/gnu166

[2] McCusker, J., Cole, M.G., Voyer, P., Vu, M., Ciampi, A., Monette, J. and Dyachenko, A. (2013) Environmental Factors Predict the Severity of Delirium Symptoms in Long-Term Care Residents with and without Delirium. Journal of the American Geriatrics Society, 61, 502-511. https://doi.org/10.1111/jgs.12164

[3] Algase, D.L., Beattie, E.R., Antonakos, C., Beel-Bates, C.A. and Yao, L. (2010) Wandering and the Physical Environment. American Journal of Alzheimer's Disease \& Other Dementias ${ }^{\oplus}, 25,340-346$. https://doi.org/10.1177/1533317510365342

[4] Tanaka, M. and Hoshiyama, M. (2014) Effects of Environmental Stimulation on Recognition of Mealtimes in Patients with Dementia. Physical \& Occupational Therapy in Geriatrics, 32, 112-122. https://doi.org/10.3109/02703181.2014.890266

[5] Hung, L. and Chaudhury, H. (2011) Exploring Personhood in Dining Experiences of Residents with Dementia in Long-Term Care Facilities. Journal of Aging Studies, 25, 1-12. https://doi.org/10.1016/j.jaging.2010.08.007 
[6] Marsden, J.P., Meehan, R.A. and Calkins, M.P. (2001) Therapeutic Kitchens for Residents with Dementia. American Journal of Alzheimer's Disease \& Other Dementias ${ }^{\oplus}, 16,303-311$. https://doi.org/10.1177/153331750101600509

[7] Campo, M. and Chaudhury, H. (2012) Informal Social Interaction among Residents with Dementia in Special Care Units: Exploring the Role of the Physical and Social Environments. Dementia, 11, 401-423. https://doi.org/10.1177/1471301211421189

[8] Marquardt, G., Johnston, D., Black, B.S., Morrison, A., Rosenblatt, A., Lyketsos, C. G. and Samus, Q.M. (2011) Association of the Spatial Layout of the Home and ADL Abilities among Older Adults with Dementia. American Journal of Alzheimer's Disease \& Other Dementias ${ }^{\oplus}$, 26, 51-57. https://doi.org/10.1177/1533317510387584

[9] Edwards, C.A., McDonnell, C. and Merl, H. (2013) An Evaluation of a Therapeutic Garden's Influence on the Quality of Life of Aged Care Residents with Dementia. Dementia, 12, 494-510. https://doi.org/10.1177/1471301211435188

[10] Fleming, R., Goodenough, B., Low, L.F., Chenoweth, L. and Brodaty, H. (2016) The Relationship between the Quality of the Built Environment and the Quality of Life of People with Dementia in Residential Care. Dementia, 15, 663-680. https://doi.org/10.1177/1471301214532460

[11] Torrington, J. (2007) Evaluating Quality of Life in Residential Care Buildings. Building Research \& Information, 35, 514-528. https://doi.org/10.1080/09613210701318102

[12] Smit, D., Willemse, B., de Lange, J. and Pot, A.M. (2014) Wellbeing-Enhancing Occupation and Organizational and Environmental Contributors in Long-Term Dementia Care Facilities: An Explorative Study. International Psychogeriatrics, 26, 69-80.

[13] Milte, R., Shulver, W., Killington, M., Bradley, C., Ratcliffe, J. and Crotty, M. (2016) Quality in Residential Care from the Perspective of People Living with Dementia: The Importance of Personhood. Archives of Gerontology and Geriatrics, 63, 9-17. https://doi.org/10.1016/j.archger.2015.11.007

[14] Calkins, M.P. (2009) Evidence-Based Long Term Care Design. Neuro Rehabilitation, $25,145-154$.

[15] Day, K., Carreon, D. and Stump, C. (2000) The Therapeutic Design of Environments for People with Dementia: A Review of the Empirical Research. The Gerontologist, 40, 397-416. https://doi.org/10.1093/geront/40.4.397

[16] Heidegger, M. (1962) Being and Time. Trans. Macquarrie, J. and Robinson, E.

[17] Heidegger, M. (1971) Building Dwelling Thinking. Poetry, Language, Thought, 154.

[18] Sarvimäki, A. (2006) Well-Being as Being Well-A Heideggerian Look at Well-Being. International Journal of Qualitative Studies on Health and Well-Being, 1, 4-10. https://doi.org/10.1080/17482620500518101

[19] Merleau-Ponty, M. (1962) Phenomenology of Perception [Phénoménologie de la Perception]. Routledge \& Kegan Paul.

[20] Seamon, D. (2014) Merleau-Ponty, Perception, and Environmental Embodiment: Implications for Architectural and Environmental Studies. Carnal Echoes. Merleau-Ponty and the Flesh of Architecture.

[21] Seamon, D. (1979) A Geography of the Lifeworld: Movement, Rest, and Encounter. Croom Helm, London.

[22] Gillett-Swan, J.K. and Sargeant, J. (2015) Wellbeing as a Process of Accrual: Beyond Subjectivity and beyond the Moment. Social Indicators Research, 121, 135-148. https://doi.org/10.1007/s11205-014-0634-6 
[23] Wrathall, M.A. (2009) Existential Phenomenology. In: Dreyfus, H.L. and Wrathall, M.A., Eds., A Companion to Phenomenology and Existentialism, Vol. 35, John Wiley \& Sons.

[24] Todres, L. and Galvin, K. (2010) "Dwelling-Mobility": An Existential Theory of Well-Being. International Journal of Qualitative Studies on Health and Well-Being, 5, 5444. https://doi.org/10.3402/qhw.v5i3.5444

[25] Lawton, M.P. (1983) Environment and Other Determinants of Well-Being in Older People. The Gerontologist, 23, 349-357. https://doi.org/10.1093/geront/23.4.349

[26] Nahemow, L. (2000) The Ecological Theory of Aging: Powell Lawton's Legacy. In: Rubinstein, R., Moss, M. and Kleban, M., Eds., The Many Dimensions of Aging, $22-40$.

[27] Lawton, M.P. (1994) Quality of Life in Alzheimer Disease. Alzheimer Disease \& Associated Disorders, 8, 138-150. https://doi.org/10.1097/00002093-199404000-00015

[28] Nordbakke, S. and Schwanen, T. (2014) Well-Being and Mobility: A Theoretical Framework and Literature Review Focusing on Older People. Mobilities, 9, 104-129. https://doi.org/10.1080/17450101.2013.784542

[29] Andrews, G.J., Chen, S. and Myers, S. (2014) The "Taking Place" of Health and Wellbeing: Towards Non-Representational Theory. Social Science \& Medicine, 108, 210-222. https://doi.org/10.1016/j.socscimed.2014.02.037

[30] Gesler, W.M. (1992) Therapeutic Landscapes: Medical Issues in Light of the New Cultural Geography. Social Science \& Medicine, 34, 735-746. https://doi.org/10.1016/0277-9536(92)90360-3

[31] Williams, A. (1998) Therapeutic Landscapes in Holistic Medicine. Social SCIENCE \& Medicine, 46, 1193-1203. https://doi.org/10.1016/S0277-9536(97)10048-X

[32] Milligan, C., Gatrell, A. and Bingley, A. (2004) "Cultivating Health": Therapeutic Landscapes and Older People in Northern England. Social Science \& Medicine, 58, 1781-1793. https://doi.org/10.1016/S0277-9536(03)00397-6

[33] Williams, A. (2002) Changing Geographies of Care: Employing the Concept of Therapeutic Landscapes as a Framework in Examining Home Space. Social Science \& Medicine, 55, 141-154. https://doi.org/10.1016/S0277-9536(01)00209-X

[34] Willis, A. (2009) Restorying the Self, Restoring Place: Healing through Grief in Everyday Places. Emotion, Space and Society, 2, 86-91. https://doi.org/10.1016/j.emospa.2009.09.001

[35] Diaz-Ponce, A. and Cahill, S. (2013) Dementia and Quality-of-Life Issues in Older People. In Aging in European Societies, Springer US, 97-115. https://doi.org/10.1007/978-1-4419-8345-9_7

[36] Jonker, C., Gerritsen, D.L., Bosboom, P.R. and Van der Stehen, J.T. (2004) A Model for Quality of Life Measures in Patients with Dementia: Lawton's Next Step. Dementia and Geriatric Cognitive Disorders, 18, 159-164. https://doi.org/10.1159/000079196

[37] Lawton, M.P. and Rubinstein, R.L. (2000) Interventions in Dementia Care: Toward Improving Quality of Life. Springer Publishing Company.

[38] Chalfont, G.E. (2007) Wholistic Design in Dementia Care: Connection to Nature with PLANET. Journal of Housing for the Elderly, 21, 153-177. https://doi.org/10.1300/J081v21n01_08

[39] Gonzalez, M.T. and Kirkevold, M. (2014) Benefits of Sensory Garden and Horticultural Activities in Dementia Care: A Modified Scoping Review. Journal of Clinical Nursing, 23, 2698-2715. https://doi.org/10.1111/jocn.12388 
[40] Block, N.J., Flanagan, O.J. and Güzeldere, G. (Eds.) (1997) The Nature of Consciousness: Philosophical Debates. MIT Press.

[41] WHO (2017) Dementia Fact Sheet. http://www.who.int/mediacentre/factsheets/fs362/en/

[42] Wilson, M. (2002) Six Views of Embodied Cognition. Psychonomic Bulletin \& Review, 9, 625-636. https://doi.org/10.3758/BF03196322

[43] Barsalou, L.W. (1999) Perceptions of Perceptual Symbols. Behavioral and Brain Sciences, 22, 637-660. https://doi.org/10.1017/S0140525X99532147

[44] Johnson, M. (1987) The Body in the Mind: The Bodily Basis of Imagination, Reason, and Meaning. In: The Body in the Mind: the Bodily Basis of Imagination, Reason and Meaning.

[45] Hampson, P.J. and Morris, P.E. (1996) Understanding Cognition. Blackwell, Oxford.

[46] Galvin, K. and Todres, L. (2011) Kinds of Well-Being: A Conceptual Framework That Provides Direction for Caring. International Journal of Qualitative Studies on Health and Well-Being, 6, 1-13. https://doi.org/10.3402/qhw.v6i4.10362

[47] Tuan, Y.F. (1977) Space and Place: The Perspective of Experience. U of Minnesota Press.

[48] Seamon, D. (2007) A Lived Hermetic of People and Place: Phenomenology and Space Syntax. In Proceedings, 6th International Space Syntax Symposium, iii01-16.

[49] Shaw, R.L., West, K., Hagger, B. and Holland, C.A. (2016) Living Well to the End: A Phenomenological Analysis of Life in Extra Care Housing. International Journal of Qualitative Studies on Health and Well-Being, 11, 31100.

https://doi.org/10.3402/qhw.v11.31100 